\title{
DELTA PHASE AND DEFORMATION FRACTURE BEHAVIOUR OF INCONEL 718 ALLOY
}

\author{
Zhang Yun, Huang Xuebing, Wang Yong, Yu Weicheng, Hu Zhuangqi \\ Institute of Metal Research \\ Chinese Academy of Sciences \\ Shenyang 110015 \\ People's Republic of China
}

\begin{abstract}
$\underline{\text { Abstract }}$
The deformation characteristics of In718 alloy in two heat treatment states were investigated using thin foil specimens during in-situ tensile experiment in TEM. The results indicated that during the process of long-term aging the equilibrium $\delta$ phase annexed $\gamma^{\prime \prime}$ phase and grew, which was accompanied by the formation of $\gamma^{\prime \prime}$ free zone around $\delta$ precipitates area. Due to the existence of many mismatched structures in different $\gamma^{\prime \prime}$ phases, the $\delta$ phase tablets, which transformed from different $\gamma^{\prime \prime}$ phases particles, appeared in a pattern of fasciculation. During the deformation process, $\delta$ phase guided crack to advance in a zigzag way along $\delta$ phases in grains and at grain boundaries, resulted in absorbing lots of strain energy and increasing the plasticity of the alloy. The width of deformation area in front and sides of the crack could be $70 \mu \mathrm{m}$ and $43 \mu \mathrm{m}$ respectively. In normal heat treatment condition, $\gamma^{\prime}$ and $\gamma^{\prime \prime}$ phases were not only small in amount and little in size, but also coherent with matrix, therefore slip lines were straight, fine and dense. However, $\delta$ phase at grain boundaries was less and discontinuous, resulting in crack propagation along grain boundaries and showing less plasticity.
\end{abstract}

\footnotetext{
Superalloys 718, 625, 706 and Various Derivatives Edited by E.A. Loria

The Minerals, Metals \& Materials Society, 1997
} 


\section{Introduction}

The precipitation characteristics and strengthening mechanism of metastable $\gamma^{\prime}$ and $\gamma^{\prime \prime}$ phase in commercial In $718 \mathrm{Fe}-\mathrm{Ni}$ base alloy as well as the influence of these phases on the properties of the alloy have been widely investigated and reported (1-3). The transformation relationship between $\gamma^{\prime \prime}$ and $\delta$ phase has been carefully observed and theoretically confirmed(1), indicating that the equilibrium $\delta$ phase nucleates at $\gamma^{\prime \prime}$ phase at temperatures below $1173 \mathrm{~K}$, while $\delta$ phase directly precipitates in austenite matrix at higher ageing temperatures. It is well known that equilibrium $\delta$ phase has very important influence on mechanical properties of In718 alloy. People has used different working and heat treatment methods to control the amount, morphology and distribution of $\delta$ phase and improve the plasticity of the alloy. Especially, it has been the fact that $\delta$ phase has been used to increase crack propagation resistance $(4,5)$. The aim of this paper is to study the relationship between $\delta$ phase and deformation fracture and explore the cause for $\delta$ phase to improve the plasticity of the alloy.

\section{Experimental}

The chemical composition of Inconel 718 used in this study in wt. pct.was as follows: $19.07 \mathrm{Cr}$; $3.04 \mathrm{Mo} ; 5.03 \mathrm{Nb} ; 0.53 \mathrm{Al} ; 1.05 \mathrm{Ti} ; 0.07 \mathrm{Si} ; 0.002 \mathrm{~S} ; 0.0005 \mathrm{P} ; 0.029 \mathrm{C} ; 0.0055 \mathrm{~B} ; 53.19 \mathrm{Ni}$; balance $\mathrm{Fe}$. The experimental material was heat treated by manufacturer as follows: The normal heat treatment was (1) $950^{\circ} \mathrm{C} / 1 \mathrm{~h}$ air cooled $+720^{\circ} \mathrm{C} / 8 \mathrm{~h}$ furnace cooled $+620^{\circ} \mathrm{C} / 8 \mathrm{~h}$ furnace cooled. The long-term aging treatment was (2) the normal heat treatment + $650^{\circ} \mathrm{C} / 1500 \mathrm{~h}$ air cooled.

The appearance and distribution of $\delta$ phase were observed by SEM. In-situ tensile tests were conducted on the micro- tensile stage of Philips EM420 TEM. the magnified photo of which is shown in Fig.1.The tensile rate was $0.5 \mu \mathrm{m}-1.0 \mu \mathrm{m} / \mathrm{s}$. During the tensile process the slip deformation and fracture characteristics of foil sample surface were observed. Of course, thin foil sample was in plane stress state. When taking photo, the strain amount was kept constant. During the process of observing crack propagation, the tensile rate was kept constant.

After being cut into slices, the samples were mechanically polished to $30 \mu \mathrm{m}$ in thickness, then were thinned to $5-10 \mu \mathrm{m}$ (the edge thickness of a central hole) by double jet electrolytic polishing technique. The size of final samples with a central hole for in-situ observation was $5 \mathrm{~mm} \times 25 \mathrm{~mm}$. The composition of electrolytic polishing solution was $10 \%$ perchloric acid alcohol solution and electrolytic polishing was performed at $-30^{\circ} \mathrm{C}$.

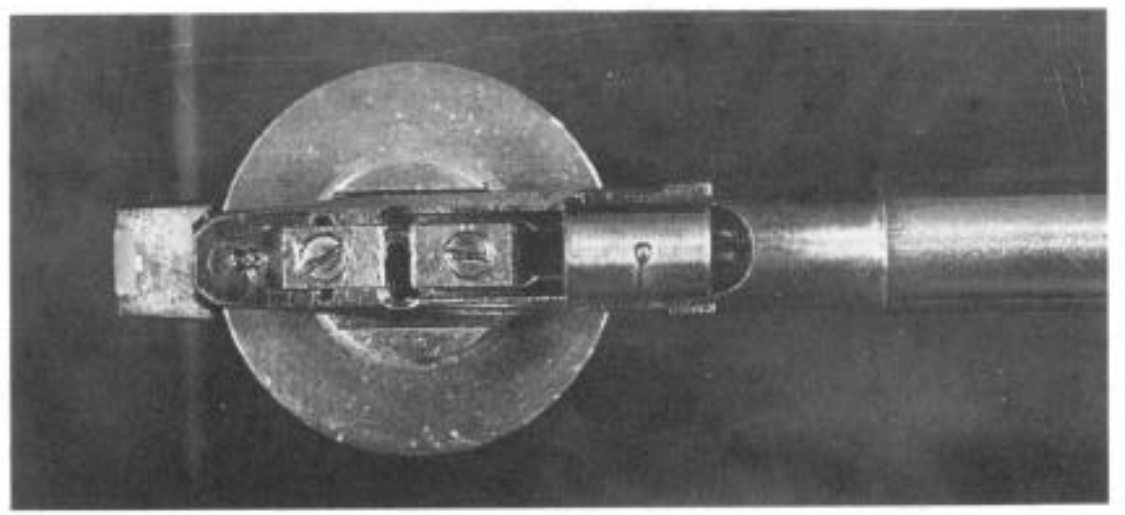

Figure 1 - Micro tensile stage 


\section{Results and Discussion}

\section{8 phase precipitate}

$\delta-\mathrm{Ni}_{3} \mathrm{Nb}$ phase is acted as a strengthening phase at grain boundaries of deformed In 718 alloy. Delta phase was distributed discontinuously at grain boundaries under normal heat treatment condition as shown in Fig.2 (a) and (c). After long-term aging strengthening $\gamma^{\prime \prime}$ phase grew up and its volume fraction amount increased obviously. In addition equilibrium $\delta$ phase annexed $\gamma^{\prime \prime}$ phase and grew, which was accompanied by the formation of $\gamma^{\prime \prime}$ free zone around $\delta$ precipitates area. It is clearly shown in Fig.2(b) and (d) that after deep etching the biggest teblet $\delta$ phase had about $5 \mu \mathrm{m}$ long, $3 \mu \mathrm{m}$ wide and $0.5 \mu \mathrm{m}$ thick. Tablet and needleshaped $\delta$ phase was distributed at a rather wide boundary area and was extended to intragranular sites. Sometimes $\delta$ phase precipitated in grain interior and showed a parallel array or displayed a cluster appearance with several orientation relationships. This is because the orientation relationship between the matrix and the $\delta$ phase was determined to be: $\{111\}_{\gamma} / /(010)_{5} ;\langle 1 \overline{1} 0\rangle_{\gamma} / /[100]_{\delta}$, in conformity with that reported by Kirman [6]. The habit planes of the $\delta$ precipitates were determined to be the $\{111\}_{\gamma}$ plane. Four precipitate variants occurred in the austenite matrix (indicated by arrow ). As described earlier[4,6,7], $\delta$ phase has obvious influence on crack propagation under creep and fatigue condition for In 718 alloy. It is very beneficial that the investigation on the influence of $\delta$ phase on deformation and fracture is made through two kinds of structures with different precipitation characteristics.
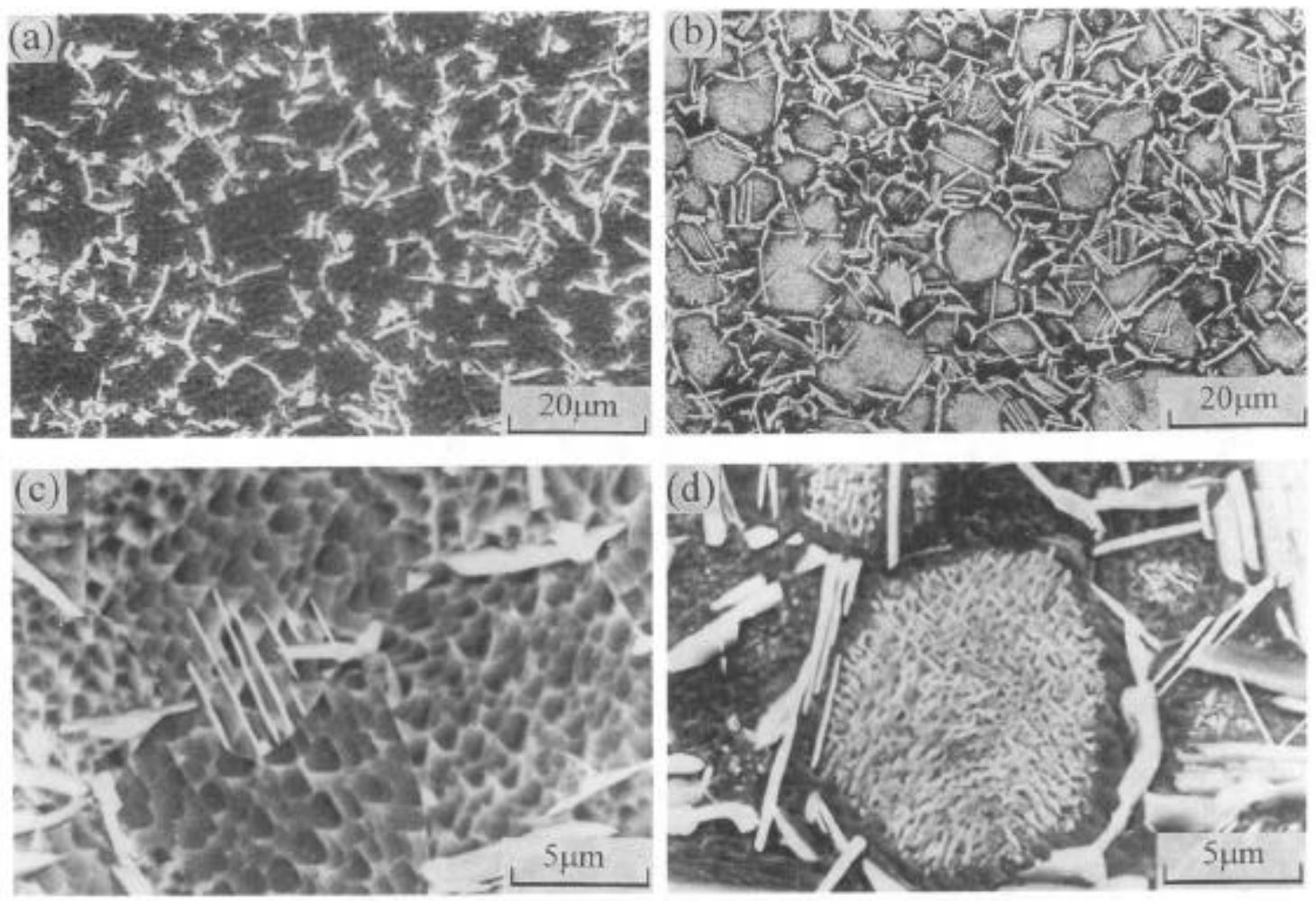

Figure 2 - Microstructure of In 718 alloy $(a, c)$ In normal heat treament state (b,d) In long-term aged state 

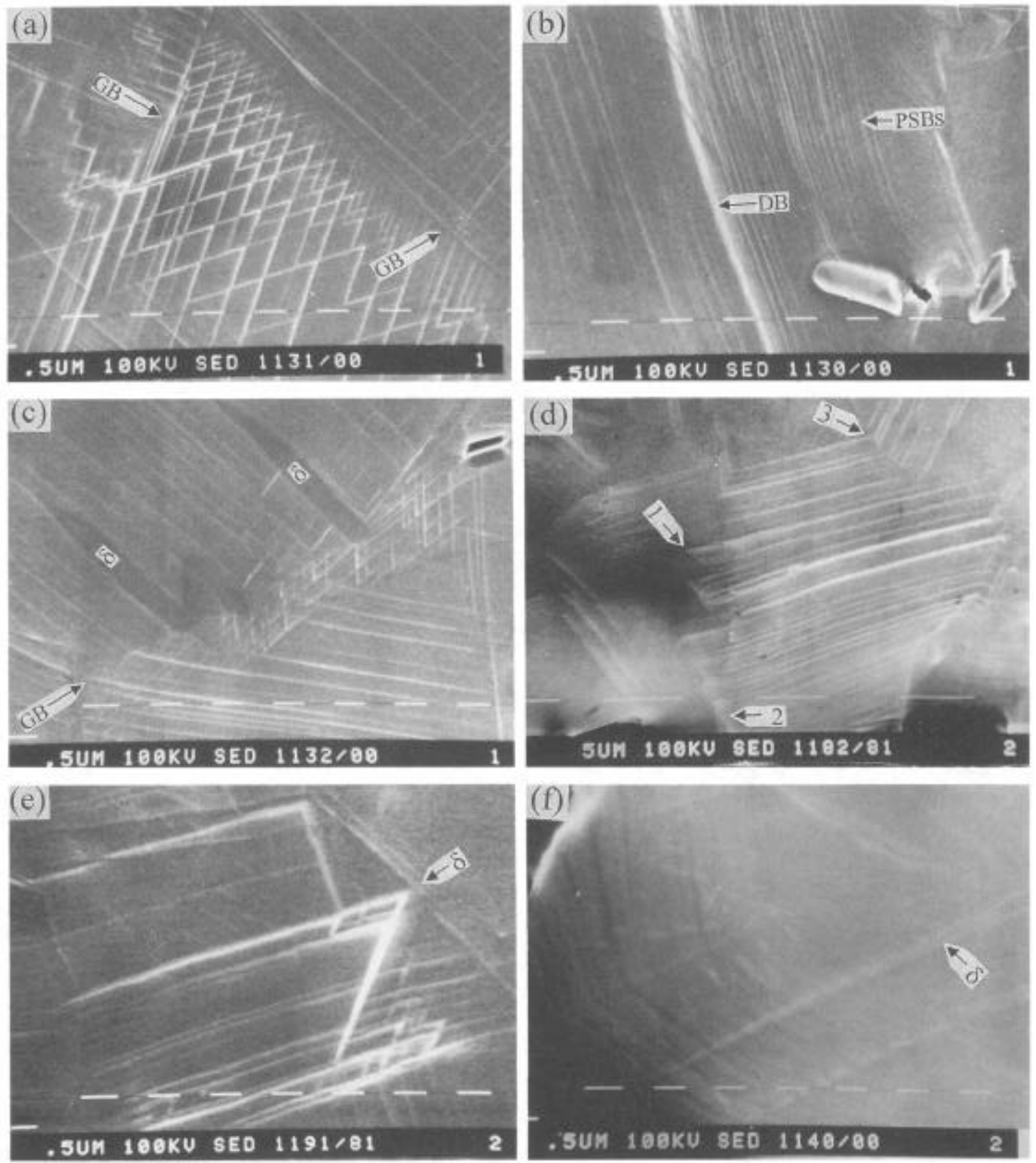

Figure 3 - Deformation characteristics of experimental 718 alloy $(\mathrm{a}, \mathrm{b}, \mathrm{c})$ In normal heat treament state $(\mathrm{d}, \mathrm{e}, \mathrm{f})$ In long-term aged state

\section{8 Phase and Deformation Behaviour}

Fig.3(a),(b) and (c) show the deformation characteristics of sample surface in normal heat treatment state during in-situ tensile process. After tensile test began, dislocations in the sample were set in motion and when the easy slip direction in some grains was just similar with the direction of the maximum shear stress, dislocations moved rather dramatically, forming primary slip band (PSBs). The stress axis in Fig. 3 is in a vertical direction. PSBs were observed firstly in side grains, then multiple slip system began to move in middle grain. The PSBs were uniform and fine in slip area in front of the crack, with width 
being less than $0.1 \mu \mathrm{m}$ and average distance between slip bands being $0.4 \mu \mathrm{m}$. Deformation band, buckle, void or crack nucleation were not observed yet at triple point of grain boundaries with increasing stress. Observation indicated that adjacent grains had a good coordination and the matrix had higher plasticity. In the area shown in Fig.3(b) slip lines were long and right, fine and dense. There was also micro-deformation band as indicated by an arrow. This is because, after the slip band was formed, usually a soft area appeared, secondary slip often continued to occur along some primary slip planes. The concentrated slip was extruded out on the surface and the micro-deformation band was formed. It also can be seen in the figure that voids nucleated at the edges of inclusions due to stress concentration or inclusions were extruded out. $\delta$ phase in In 718 alloy usually precipitated along $\{111\}_{\gamma}$ plane, being consistent with slip direction as shown in Fig.3(c). The figure also shows that the slip band impinged on grain boundaries, producing additional slip band, where is the channel for crack to propagate easily. Fig.3(d),(e) and (f) display the deformation characteristics of samples, which experienced long-term aging. In Fig.3(d) slip band was only fully distributed in the middle grain among adjacent grains, but there was big difference in the width of slip band and the distance between slip bands compared with the alloy in normal heat treatment state. The width of slip bands was about $0.4-0.6 \mu \mathrm{m}$ and the average distance between slip band was 1.0$1.3 \mu \mathrm{m}$. There were also two shear bands and a so-called local movement of grain boundary ( marked by arrow 1). There existed heterogeneous slip in other grains. The relationship between $\delta$ phase and slip is worth noticing. The slip lines in grains shown in Fig.3(d) were directly extended into needle-shaped $\delta$ phase at grain boundaries (indicated by arrow 2). Slip lines could continuously cross grain boundaries without $\delta$ phase, i.e., the slip lines in both sides of the grain boundaries had corresponding relationship but different directions ( marked by arrow 3). The heterogeneous slip lines in Fig.3(e) were retarded by $\delta$ phase, but crack did not nucleate at the intersecting point of slip lines and $\delta$ phase. Fig.3(f) shows intrusion and extrusion at the intersecting point of slip lines and $\delta$ phase.

Some conclusions can be drawn from the comparison of deformation characteristics between two kinds of heat treated alloys. In the normal heat treated alloy the strengthening $\gamma^{\prime \prime}$ phase is finer and there is less equilibrium $\delta$ phase (Fig.2(a) and (c)). The matrix has higher plasticity and easily produces uniform deformation under the action of external force, forming fine and dense slip band. When slip lines intersect with bulky inclusions or carbides, voids can be formed due to stress concentration. Secondly, in the long-term aged alloy strengthening $\gamma^{\prime \prime}$ phase grows. At the same time, there are many big needle and tablet shaped $\delta$ accompanied by $\gamma^{\prime \prime}$ free zone around $\delta$ precipitates (Fig.2(b) and (d)), resulting in nonuniform slip. However, needle-shaped $\delta$ phase retards slip, voids and cracks do not nucleate at the intersecting points of $\delta$ phase and slip lines. This may be an advantage of the structure.

\section{Crack Propagation and Fracture}

Fig.4 is the photo of crack propagation taken by SED accessory of TEM. Stress axis is in the vertical direction. As can be found from Fig.4(a), the crack in the normal heat treated alloy mainly propagated along the slip direction at about $45^{\circ}$ angle with stress axis. With increasing stress, micro-deformation occurred in front of the crack. As indicated by the arrow 1 and 2, the inclusion in the stress concentrated area was extruded out (Fig.4(b), corresponding to arrow 1) or void nucleated at the deformation band (Fig.4(c), corresponding to arrow 2). But there were a lot of single slip and multiple slip before the occurrence of the phenomenon mentioned above. The crack propagated along the favorable PSB and often changed the direction at the site of cross-slip, then connected defects such as inclusion and void. On the other hand, a totally different phenomenon occurred in the long-term aged alloy. The width of deformation area in front and sides of the crack could be $70 \mu \mathrm{m}$ and $43 \mu \mathrm{m}$ respectively. These values were more 

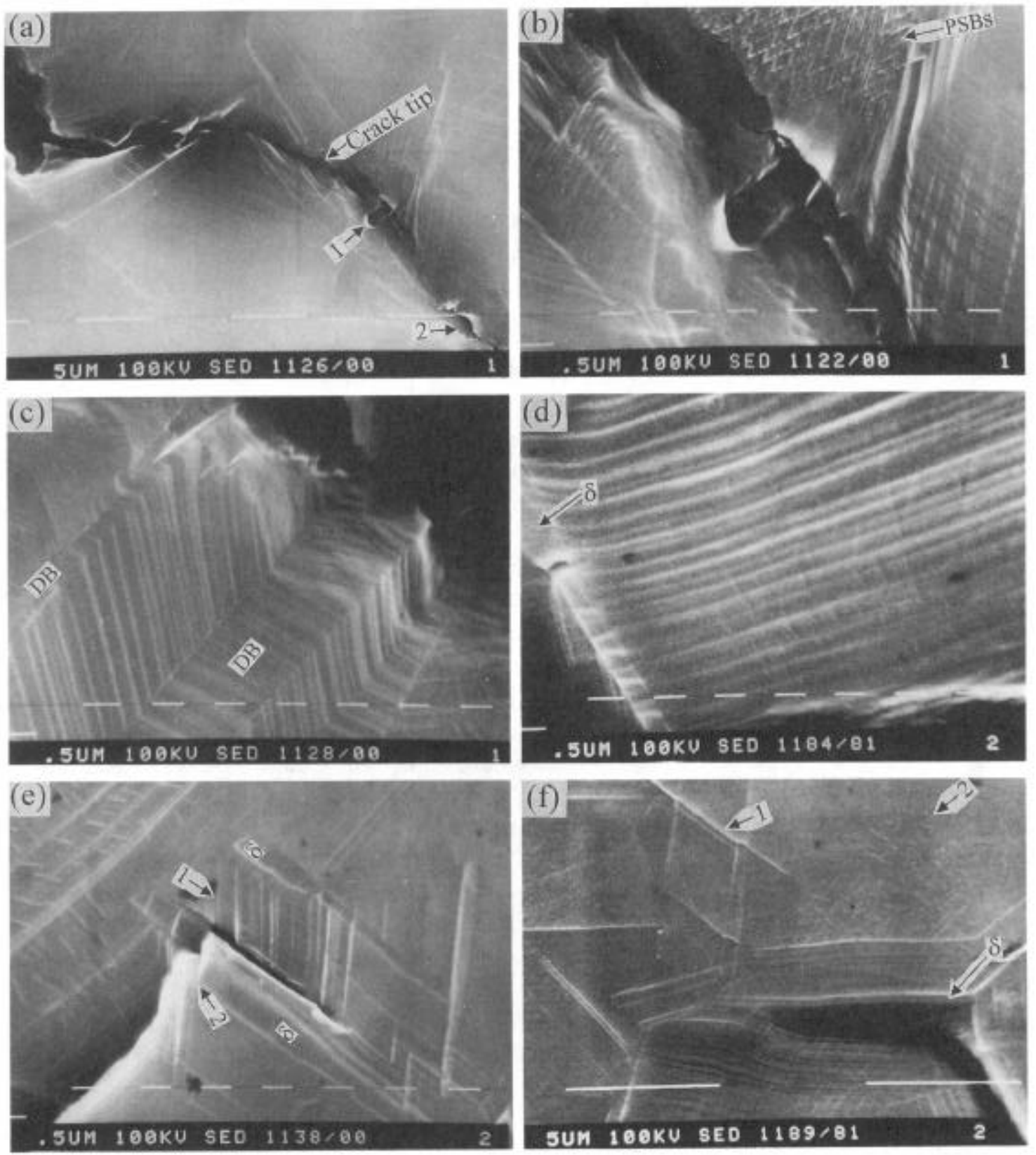

Figure $4-$ Crack propagation of 718 alloy with two different heat treatments $(a, b, c)$ In normal heat treament state $(d, e, f)$ In long-term

than those for normal heat treatment state. As shown in Figrue.4 (d), the void nucleated at the intersection point of slip lines and $\delta$ phase, but it did not propagate. Meanwhile the crack propagated along the direction parallel to needle $\delta$ phase. An example is given in Fig.4(e), in which the crack was retarded by $\delta$ phase and its propagation direction was changed. At first, the place between two $\delta$ phases became a soft area (marked by arrow 1) due to $\gamma^{\prime \prime}$ phase depletion (Fig.2(d)) and multiple slip occurred under the action of external force. At the same time, there was a few local slip lines in the adjacent area so-called a hard area. It also can be seen that after slip lines impinged on $\delta$ phase, the slip direction was echanged. The 

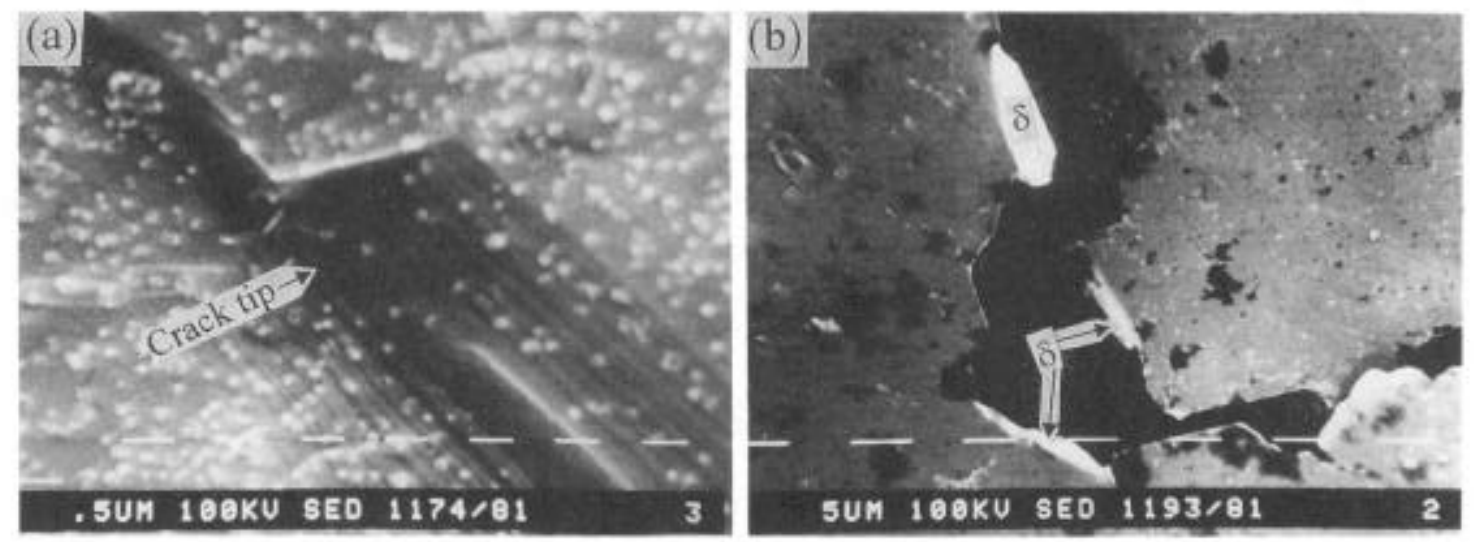

Figure 5 - Crack morphology of two kinds of heat treatment state (a) In normal heat treament state (b) In long-term aged state
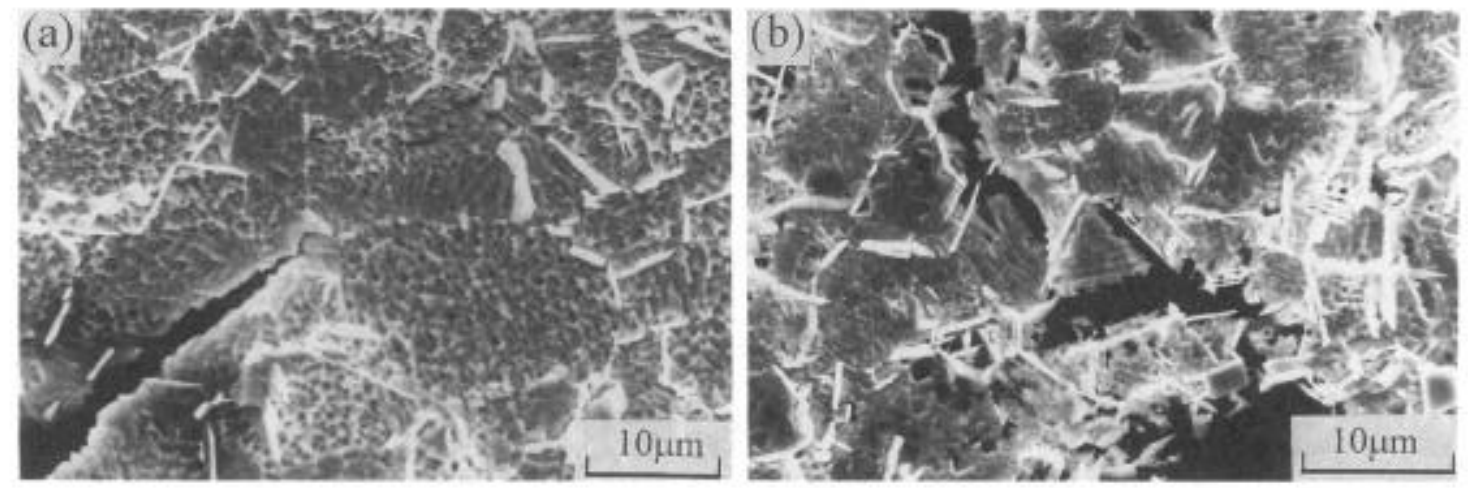

Figure 6 - Crack tip morphology of experimental 718 alloy
(a) In normal heat treament state
(b) In long-term aged stat

bigger $\delta$ phase intersected with concentrated slip bands and fracture occurred, as shown by arrow 2 in the figure. Then the crack turned to the direction parallel to $\delta$ phase. As indicated by arrow 1 in Fig.4(f), there was coarser slip band in the both sides of most $\delta$ phase needles, and the crack often propagated along the edge between coarser slip bands and $\delta$ phase. At the same time there was a hard zone without PSB due to the existence of many $\gamma^{\prime \prime}$ phase particles (marked by arrow 2). Fig.5 confirmed that the crack in the normal heat treated alloy propagated along slip lines (Fig.5(a)) and the crack was quite right; while in the longterm aged alloy $\delta$ phase was fully distributed in the adjacent area of the crack and the crack was in a zigzag path (Fig. 5(b)). After deep etching, the tensile tested foil specimen was observed on SEM and the phenomenon mentioned above was further confirmed, i.e., the crack in the normal heat treated alloy was right and propagated along grain boundaries (Fig.6a), while the crack in the long-term aged alloy was in a zigzag way. Many secondary microcracks were induced beside most $\delta$ phase in the adjacent area of the primary crack, indicating the guiding action of $\delta$ phase in cracking.

Through lots of experimental observation it is reasonable to indicate that in the long-term aged 
In 718 alloy, a lot of $\delta$ phase precipitate in grains and at grain boundaries, which is accompanied by the occurrence of $\gamma^{\prime \prime}$ free zone around $\delta$ phase. The depleted area is a soft $\gamma$ matrix and has a higher deformation ability. When the strain concentration exceeds the threshold value, the microcrack will occur and propagate along $\delta$ phase. In addition, there is a certain orientation relationship between $\delta$ precipitates and $\gamma$ matrix. Usually there are four directions for $\delta$ precipitates in a grain, the orientations of $\delta$ phase in the entire specimen are variants. Therefore the zigzag cracks can absorb much strain energy and show higher plasticity. This is the reason for $\delta$ phase to improve the plasticity of the alloy. Although the normal heat treated alloy has a better comprehensive properties, it has less $\delta$ phase and has no $\gamma^{\prime \prime}$ depleted area, therefore shows poorer plasticity.

\section{Conclusions}

1. A lot of tablet and needle-shaped $\delta$ phase precipitates at grain boundaries and in grains in long - term aged $\left(650^{\circ} \mathrm{C} / 1500 \mathrm{~h}\right)$ In 718 alloy, which is accompanied by the occurrence of $\gamma^{\prime \prime}$ phase free zone around $\delta$ phase.

2. In normal heat treated In 718 alloy, under the action of tensile stress, slip bands are fine, dense and uniform. Void usually nucleates at the intersecting point between inclusion and slip bands. The cracks propagate along slip bands and grain boundaries.

3. In the long - term aged In 718 alloy, under the action of tensile stress, slipping is localized. Coarse slip band and deformation band often occur around $\delta$ phase. The cracks propagate along the boundary of $\delta$ phase, $\delta$ phase plays a guiding role in cracking, resulting in a zigzag path and improving the plasticity of the alloy.

\section{$\underline{\text { References }}$}

1. M.Sundararaman, P.Mukhopadhyay and S.Banerjee, Precipitation and Room Temperature Deformation Behaviours of Inconel 718, "The Superalloys 718, 625, 706 and Various Derivatives", ed., E.A.Loria, The Minerials \& Materials Society, (1994) 419.

2. D.R.Muzyka, The Superalloys, ed., C.T. Sims and N.C. Hagel. (New York, NY: John Wiley), (1972) 113.

3. D.F.Paulonis, J.M.Oblak and D.S.Durall, Trans.ASM.,62 (1969) 611.

4. Shuqi Li, Jingyun Zhuang, Jinyan Yang, Qun Deng and Jinhui Du, The Effect of $\delta$-Phese on Crack Propagation Under Creep and Fratigue Conditions In Alloy 718, “ The Superalloys $718,625,706$ and Various Derivatives", cd., E. A. Loria, The Minerals, Metals \& Materials Society, (1994) 545.

5. Xie Xishan, High Temperature Strengthening and Ductility Improvement in Supperalloys "Proceedings of Second National Conference on High Temperature Strength", China, (1988) 14.

6. Kirman, "Precipitation in the Fe-Ni-Cr-Nb System", J. Iron and Steel Institute, 207 (1969) 1612.

7. W.Chen and M.C.Chaturvedi, The Influence of Grain Boundary Precipitates on Creep Fracture of Inconel 718, “The Superalloys 718, 625,706 and Various Derivatives", ed., E.A.Loria, The Minerals \& Materials Society, (1994) 567. 